\title{
Retained subretinal perfluorocarbon in multimodal image
}

\section{Elena Guzmán Almagro', Rosario Cobo Soriano ${ }^{1,2}$, Irene Fuentes-Vega ${ }^{1}$, Ana Fernández Hortelano ${ }^{1}$, Julio González Martin-Moro ${ }^{1,2}$}

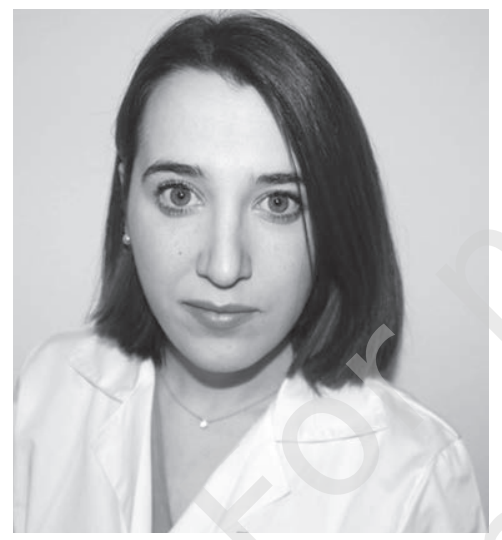

${ }^{1}$ Ophthalmology Department, University Hospital of Henares, Madrid, Spain Chair: Prof. Jorge Alio, MD, PhD ${ }^{2}$ Department of Medicine, University Francisco de Vitoria, Madrid, Spain Head: Prof. Fernando Caballero Martínez, MD, PhD

\section{H I G H L I G H T S}

Perfluorocarbon bubbles can be retained after vitreo-retinal surgery. Signs registered by multimodal image help to diagnose this condition.

\section{ABSTRACT}

Introduction: Retained subretinal perfluoro-n-octane droplets occur in nearly $1 \%$ of the procedures. When subretinal cystoid cavities are registered, differential diagnosis including this condition is needed.

Clinical case: A 77-year-old men presented three small bubbles of perfluoro-n-octane under the papillomacular bundle after vitrectomy due to a retina redetachment, evidenced by multimodal image.

Conclusions: Multimodal image can help diagnose this condition. There are several signs to support this diagnosis. If visual acuity is threatened, removing the bubbles is mandatory, but we need to acknowledge risks.

Key words: vitreo-retinal surgery, surgical complication, optical coherence tomography, multimodal image, subretinal perfluorocarbon 


\section{INTRODUCTION}

Perfluorocarbon liquids (PFCLs) are commonly used in vitreo-retinal surgery. Since their introduction in 1987, PFCLs have become an important resource in simplifying the performance of numerous surgical procedures. Being denser than water, their low viscosity and insolubility make them an essential tool in subretinal fluid drainage during retinal detachment surgery and in many other maneuvers [1].

Purified PFCLs were initially considered biologically inert [2], although in the last years conversations regarding this product have revolved around its toxicity, either chemical or physic. Due to their heavy weight, when left for a long time in the vitreous chamber they may produce histological changes such as the loss of outer retinal layers. When they are retained in the subretinal space, the bubble they form can block the contact between photoreceptors and the retinal pigment epithelium, required for their nourishment. In addition, over the last years, several clusters of acute retinal toxicity related to PFCLs have been reported in Europe [3] due to the presence of impurities. One of the best studied clusters took place in Spain, affecting 120 patients [4]. The most characteristics findings were retinal necrosis and vascular occlusion [4]. Interestingly, companies selling these products adhered to the European guidelines for toxicity testing. Nevertheless, these tests failed to identify the adverse effect. For this reason, manufactures and authorities have been required to subject to a stricter level of vigilance on conservation, testing and commercialization of PFCLs. Testing should evaluate the final product and consider its clinical use $[5,6]$.

Bubbles can be retained after surgery. We describe a case studied by multimodal image with this condition.

\section{CLINICAL CASE}

A 77-year-old male underwent vitreo-retinal surgery twice for a complicated inferior retinal detachment. PFCLs were used during both surgeries. Three small bubbles of PFCLs under the papillomacular bundle were observed at onemonth follow-up postsurgical visit. In order to register the size of the droplets and their location and to facilitate the follow-up, a fundus colour retinography was performed (fig. 1A). Red free fundus photography also emphasized the hyperautofluorescence of the PFCLs droplets (fig. 1B).

He also referred a small visual defect in his right eye that was confirmed by a visual field (fig. 2).

Spectral-domain optical coherence tomography (OCT) findings were compatible with PFCLs retained, revealing the typical Omega shape of the retina, adapted to the high surface tension of the perfluoro-n-octane drop. An acute angle is formed between the retinal pigment epithelium (RPE) and the neurosensory retina at the base of the bubble. A subtle elevation of the RPE band under the PFCLs is observed in comparison with the course of the RPE adjacent to the droplet. Due to the physical characteristics of this material, inner retinal layers are cramped and cannot be identified above the droplet. This distortion is more evident in the central point than in the periphery. An hyperreflective choroid shadow is registered in every bubble (fig. 3).

En face OCT showed hyporeflectivity areas compatible with PFCLs droplets. Inner layer microcysts were identified as the surrounding stippled hyporeflectivity (fig. 4).

The angio-OCT did not show any neovascularization (fig. 5).

\section{FIGURE ( 1}

Color (A) and red-free (B) image. A. Three droplets of perfluoro-n-octane were retained under the papillomacular bundle. B. Small circular shaped images with hyperautofluorescence correspond to the retained material.

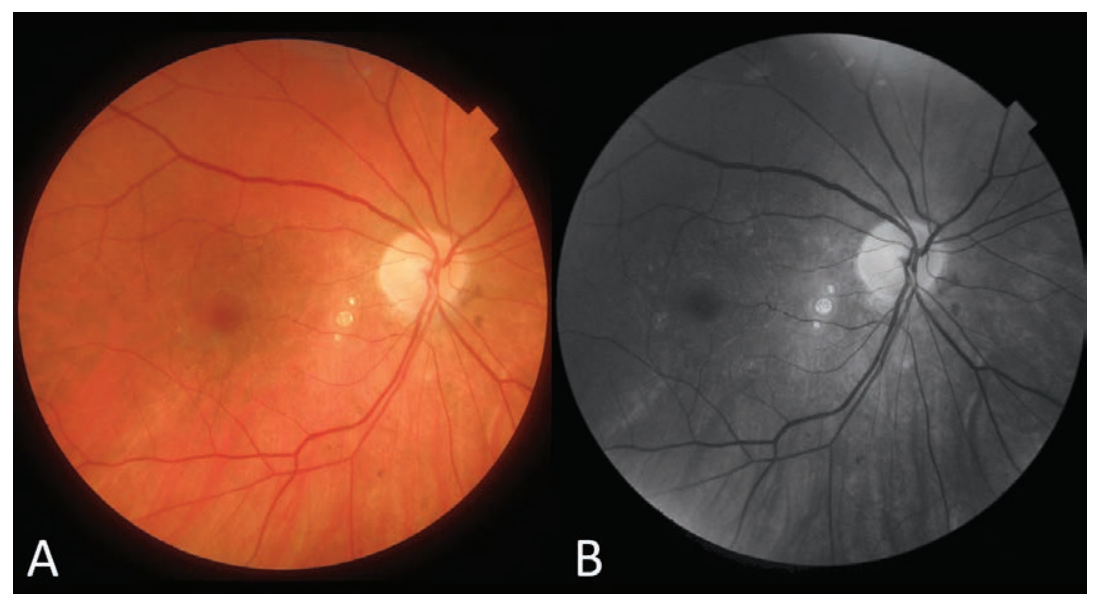




\section{FIGURE ( 2}

Scotoma registered by $24-2$ visual field with complete reliability: defects are near blind spot and fixation point, congruent to the

location of the drops.
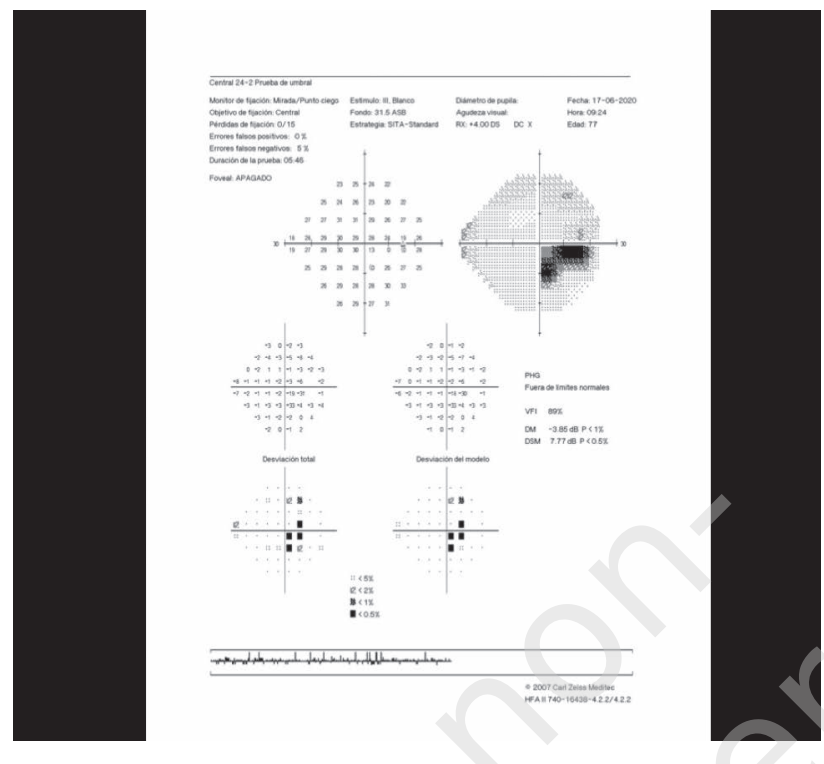

\section{FIGURE 4}

En Face OCT scan: Inner layer microcysts as smal hyporeflectivity areas (arrow head). Larger circular shaped areas of hyporeflectivity representing PFCLs droplets (star).

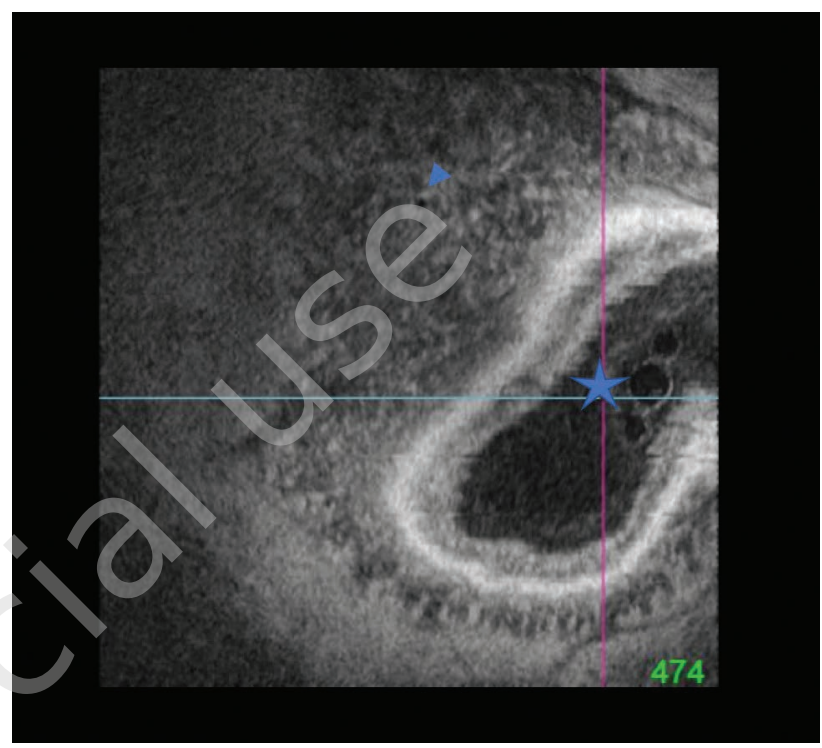

\section{FIGURE 3}

OCT scan: PFCLs bubbles in different scans. Retina with omega shape (arrow) due to the high surface tension of the droplets. Acute angle between RPE and the base of the bubble (arrow head). Choroidal shadow (star) in every droplet.

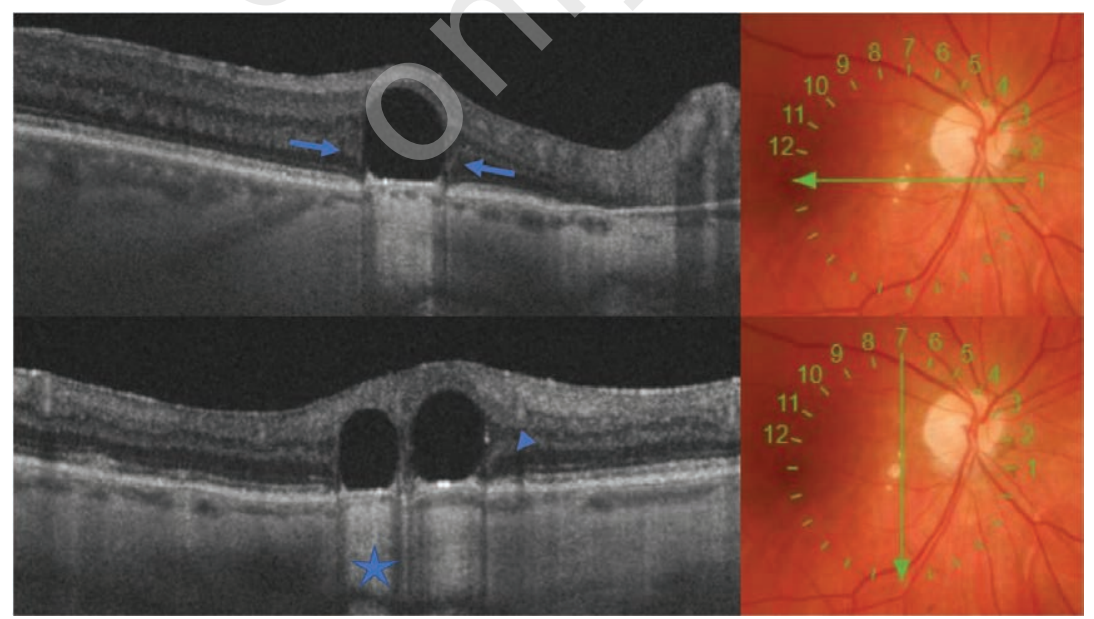




\section{FIGURE 5}

\section{OCT angiography: no signs of neovascularization.}

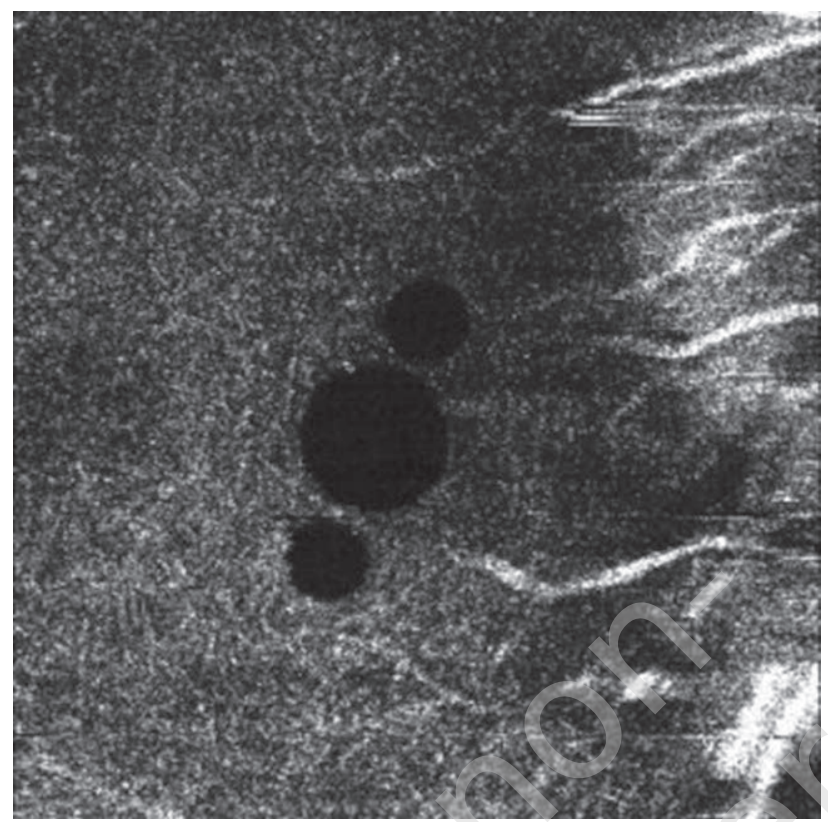

The patient has remained stable in the last two years in terms of visual acuity, visual field and funduscopy exam. Droplets have been followed by OCT every visit so as to keep measuring their size and location. Due to their stability after years and their location, no invasive procedure has been done to remove them.

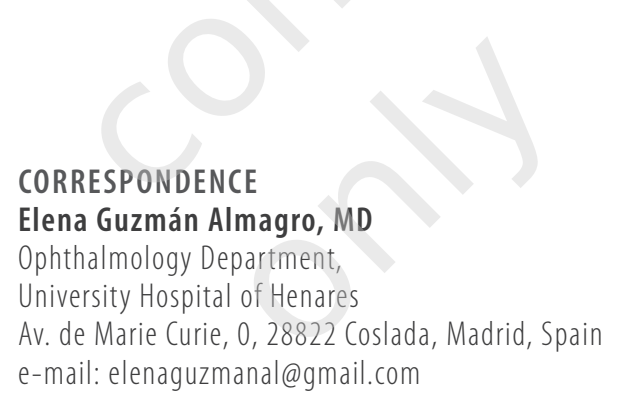

\section{ORCID}

Elena Guzmán Almagro - ID - http://orcid.org/0000-0003-4448-9293 Rosario Cobo Soriano - ID - http://orcid.org/0000-0001-6918-4301 Irene Fuentes-Vega - ID - http://orcid.org/0000-0001-5219-4140 Ana Fernández Hortelano - ID - http://orcid.org/0000-0002-3734-3707 Julio González Martin-Moro - ID - http://orcid.org/0000-0002-8056-2630

\section{References}

1. Ghoraba HH, Ghoraba HH, Heikal MA et al. Submacular perfluorocarbon liquid: long-term follow-up. Int Ophthalmol. 2020; 40: 1209-19. http://doi.org/10.1007/s10792-020-01287-7.

2. Georgalas I, Ladas I, Tservakis I et al. Perfluorocarbon liquids in vitreoretinal surgery: a review of applications and toxicity. Cutan Ocul Toxicol. 2011; 30: 251-62. http://doi.org/10.3109/15569527.2011.560915.

3. Januschowski K, Irigoyen C, Pastor JC et al. Retinal Toxicity of Medical Devices Used during Vitreoretinal Surgery: A Critical Overview. Ophthalmologica. 2018; 240: 236-43. http://doi.org/10.1159/000488504.

4. Pastor JC, Coco RM, Fernandez-Bueno I et al. Acute retinal damage after using a toxic perfluoro-octane for vitreo-retinal surgery. Retina. 2017; 37: 1140-51. http://doi.org/10.1097//AE.0000000000001680. 
5. García de Oteyza G, Elizalde J. Clinical and OCT Findings in a Case of a Presumed Perfluorooctane Retinal Acute Toxicity. Ophthalmic surgery, lasers \& imaging retina 2018; 49: 460-2. http://doi.org/10.3928/23258160-20180601-13.

6. Chang S, Simpson RN. Impure Perfluorocarbon Liquids: A Preventable Tragedy. Retina. 2017; 37: 1019-20. http://doi.org/10.1097/ IAE.0000000000001663.

7. Sigler EJ, Randolph JC, Rafieetary MR et al. Spectral domain optical coherence tomography characteristics of retained subretinal perfluoro-n-octane. Retin Cases Brief Rep. 2013; 7: 164-8. http://doi.org/10.1097/ICB.0b013e31827aee3b.

8. Figueroa MS, Contreras I. Characteristics of retained subretinal perfluoro-n-octane on optical coherence tomography. Retina. 2012; 32: 2177-8. http://doi.org/10.1097//AE.0b013e318261a6e3.

Authors' contributions:

All authors contributed equally to the article.

Conflict of interest:

None.

Financial support:

None.

Ethics:

The content presented in the article complies with the principles of the Helsinki

Declaration, EU directives and harmonized requirements for biomedical journals. 